\title{
Article
}

\section{The Agony and the Ecstasy: Student- Coaches' Perceptions of a Heutagogical Approach to Coach Development}

Stoszkowski, J., and Collins, D.

Available at http://clok.uclan.ac.uk/23280/

Stoszkowski, J., ORCID: 0000-0002-1968-5770 and Collins, D. ORCID: 00000002-7601-0454 (2018) The Agony and the Ecstasy: Student-Coaches' Perceptions of a Heutagogical Approach to Coach Development. International Sport Coaching Journal, 5 (2). pp. 136-144. ISSN 2328-918X

It is advisable to refer to the publisher's version if you intend to cite from the work. http://dx.doi.org/10.1123/iscj.2017-0077

For more information about UCLan's research in this area go to http://www.uclan.ac.uk/researchgroups/ and search for <name of research Group>.

For information about Research generally at UCLan please go to http://www.uclan.ac.uk/research/

All outputs in CLoK are protected by Intellectual Property Rights law, including Copyright law. Copyright, IPR and Moral Rights for the works on this site are retained by the individual authors and/or other copyright owners. Terms and conditions for use of this material are defined in the policies page. 
Running Head: Perceptions of a Heutagogical Approach to Coach Development

3 The Agony and the Ecstasy: Student-Coaches' Perceptions of a Heutagogical Approach to Coach Development

5

6

John Stoszkowski* and Dave Collins

7

8

*Corresponding author. School of Sport and Wellbeing, The University of Central 9 Lancashire, Preston, UK, PR1 2HE, Tel 01772895702. 
Perceptions of a Heutagogical Approach to Coach Development

Abstract

15 Heutagogy is the focus on self-determined learning by the learner. In a recent insights paper,

16 Stoszkowski and Collins offered a critical overview of heutagogy, highlighting the potential

17 advantages for coaching and coach education, as well as some concerns with its use. The aim

18 of the present study was to offer insight into student-coaches' experiences on a sports

19 coaching bachelor degree module that was underpinned by a heutagogical approach to

20 learning. Twenty-six student-coaches (6 females and 20 males) took part in semi-structured

21 group interviews, 19 of whom had completed an end of module survey. Data were analyzed

22 inductively and findings revealed that performance on, and perceptions of, the module

23 showed the approach was differentially effective, with three higher order themes representing

24 the student-coaches' articulation of their experiences: (a) attitudinal disposition, (b)

25 knowledge and experience, and (c) skill set. Although the findings of present study suggest

26 heutagogy is a potentially useful method in coach education, we also highlight some

27 potentially essential caveats to the use of the method.

28 Keywords: heutagogy; self-determined learning; andragogy; coach education; coach

29 learning 
Perceptions of a Heutagogical Approach to Coach Development

\section{Introduction}

After a long stagnant period, coach education has recently received an input of some theory driven progression (Cushion, Nelson, Armour, Lyle, Jones, Sandford, \& O'Callaghan, 2010). For example, the recognition of coach development as an aspect of adult learning has led to greater consideration of andragogy (the art and science of adult learning - Knowles, 1970) in the design of coach education; although notably well after the date of publication! Thus, while recent research still stresses the preference of coaches for informal learning (Stoszkowski \& Collins, 2016), as opposed to formal accreditation courses, consideration of andragogy has had an influence, albeit delayed, on several recent initiatives such as the University-based, UK Coaching Certificate Level 4 which represents the highest award for many sports (Sports Coach UK, 2015). This influence needs to be considered against the different perspectives on coach learning and development, even though some authors (e.g., Abraham \& Collins, 2011) have suggested that these perspectives agree more than they differ. Such nuances notwithstanding, there is little doubt that andragogy has offered something to the debate, albeit in the form of a useful summary about learning design, methodology and environment for adults in coaching.

However, although the influence of andragogy has hardly been rapid, another new approach has recently come hoving into view in coach education (Ayres, Price, Monk, \& McCarthy, 2016); namely, heutagogy, or the study of self-determined learning (Hase \& Kenyon, 2000). In a recent insights paper, Stoszkowski and Collins (2017) offered a critical overview of this extension from andragogy, highlighting the potential advantages for coaching and coach education. As they observed "the heutagogic learning process is characterised by highly autonomous learners taking personal responsibility for, and control of, what will be learnt, when it will be learnt and how it will be learnt" (p. 353). As such, the approach appears to offer a great deal for the self-motivated adult learner coach. From 
Perceptions of a Heutagogical Approach to Coach Development

56

57

another perspective, however, Stoszkowski and Collins also highlighted some concerns with the approach. Specifically, was the approach suitable for all? As a related issue, were there any essential precursors needed; certain levels of knowledge, motivation or perhaps even maturity, without which the heutagogic approach would be less effective? Indeed, heutagogic enthusiasts justifiably state the need for a level of maturity and independence in the learner; characteristics that are also central to the application of andragogic approaches (Knowles, 1975).

Certainly, caution is generally advisable when new techniques or methods are suggested. Several authors have stressed the complexity of interpersonal tasks such as coaching, emphasizing the consequent need to consider the pros and cons of a new approach (Collins, Martindale, Burke, \& Cruickshank, 2015; Collins \& Collins, 2016). In addition, others have highlighted the difficulties involved in making an epistemological change as part of the learning process (Entwistle \& Petersen, 2004). In sum, knowledge and careful consideration are always positive inclusions when considering the implementation of new ideas.

Accordingly, we saw the application of heutagogic approaches in coach development as an important topic for investigation. One issue we thought fundamental was the perceptions of trainee coaches who had experienced the approach, something which is currently underexplored. It has certainly been tried in some higher education environments (e.g., teacher training, Canning, 2010) and, with the delivery of bachelor degree programmes in sports coaching becoming more common (Lara-Bercial et al., 2016), this controlled setting may offer a good laboratory to test some of the potential drawbacks or delimitations to the approach in coach education. Accordingly, we asked convenience samples of undergraduate student-coaches what their experiences had been of a heutagogical approach to learning. The current paper reports what we found. 
Perceptions of a Heutagogical Approach to Coach Development

\section{Method}

82

83

84

85

86

87

88

89

90

91

92

93

94

95

96

97

\section{Participants}

The sample in the present study consisted of a module cohort of 26 sports coaching undergraduate students (six females and 20 males, $M_{\text {age }}=21.5$ years, $S D=0.81$ ). The participants, who were studying full-time at a UK university, were purposively sampled from a final year undergraduate module that employed a heutagogical framework in the design of its learning activities. At the time of data collection, 16 student-coaches were qualified at UKCC Level 1 and ten at Level 2 in a range of sports (see Table 1), with coaching experience ranging between 3 and 6 years $(M$ experience $=3.65$ years, $S D=0.89)$.

\section{Procedure}

The module in question, titled "coaching practice and reflection", aimed to facilitate heutagogy by providing opportunities for self-directed learning and professional development, with student-coaches responsible for completing a 6-month long work-based placement in a community coaching setting of their own arrangement. The module was an “optional" module, self-selected by student-coaches and studied alongside a range of compulsory modules required for the degree award. In an initial introductory workshop, the aims and intended learning outcomes of the module were outlined. A second workshop then focused on heutagogy as an educational concept, with particular focus placed on its purpose, process and potential value. Then, during the undertaking of their placement, and consistent with the protocol used by Stoszkowski and Collins (2015), the student-coaches were asked to engage as active participants and co-producers of knowledge, rather than passive consumers of content, by reflecting upon their on-going self-determined learning and practical experiences. Online group blogs, administered using WordPress (www.wordpress.com), provided the main teaching and learning environment, with student-coaches encouraged to find and share relevant resources to inform ongoing supportive discussion and exploration 
Perceptions of a Heutagogical Approach to Coach Development

106 with their peers. Each group blog (two groups with nine members, one group with eight

107 members) was private and could only be viewed by its members and the two module tutors

108 (cf. Stoszkowski \& Collins, 2015). Each student-coach's final module grade was based on the

109 quality of their individual participation in their group blog. Prior to data collection, ethical

110 approval was obtained from the authors' institutional ethics committee.

\section{Survey}

112 As part of a standard end of module review process, a survey was developed to

113 provide feedback about participants' perceptions and general experiences of the heutagogical

114 module design (Fraenkel, 2006). An initial 16-item survey was developed by the two authors

115 then reviewed for face and content validity (Dillman, 2000) by two other colleagues, both

116 experienced university lecturers in sports coaching. This process resulted in two

117 modifications, with five items removed and three new items included. Then, the revised

118 survey was evaluated for clarity and comprehensibility though a pilot study with a small

119 convenience sample of graduate student-coaches $(\mathrm{N}=5)$. The survey took between 8 and 13

120 minutes to complete, and follow-up cognitive interviews (Willis, DeMatio, \& Harris-Kojetin,

121 1999) resulted in the rewording of seven items to improve intelligibility and clarity. The final

122 version of the survey was comprised of 14 items, three of which required a yes or no

123 response; eight required an agree or disagree response; and three were totally open-ended. All

124 items had space for additional comments and asked student-coaches to state why they

125 answered as they did. Each student-coach was emailed an explanation of the study aims and

126 the voluntary nature of taking part, information about confidentiality and anonymity, and a

127 web link to the survey, which was hosted by the online survey tool SurveyMonkey

128 (www.surveymonkey.com). The first page of the survey repeated the information contained

129 in the email, and explained that all answers would remain anonymous, with student-coaches

130 notified that by "clicking" continue they would give informed consent for any submitted 
Perceptions of a Heutagogical Approach to Coach Development

131 answers to be used as data in the study. It was also made clear that, because answers were

132 anonymous, they could not be withdrawn once submitted as no identifying information would

133 be tracked or recorded at any stage of the data collection process.

\section{Group interview}

135 Following closure of the survey, the first author (an academic tutor on the module and 136 experienced coach educator, trained in qualitative research methods) conducted three follow-

137 up group interviews (one with the members of each group blog). To aid consistency, an

138 interview guide was developed based on a review of heutagogy literature, and the first

139 author's initial inductive analysis of survey responses. The interview guide was crosschecked

140 for its potential to elicit relevant responses through discussion between the two authors

141 (Creswell, 2007). To reduce the potential for inhibited responses, before each interview

142 commenced, student-coaches were reminded that participation in the research project was

143 voluntary and assurances were made that anything they said would not impact on their

144 module grade in any way (Millward, 2012). Participants were also made aware of appropriate

145 ethical considerations (e.g., declaration of confidentiality, right of withdrawal) and provided

146 their informed consent.

147 Initial questions were deliberately broad and open-ended so as not to lead the student-

148 coaches' responses in any way (e.g., "so what was the module like?" and "how would you

149 describe your experiences on the module?"), followed by more specific questions relating to

150 the student-coaches' personal perceptions of their experiences of (and performance under)

151 what was intended to be a heutagogical approach to learning (e.g., "why do you think you

152 enjoyed that aspect in particular?" and "how did that compare to what you're used to?").

153 Follow-up probes were used where appropriate to clarify and explore these ideas further (e.g.,

154 “could you provide a specific example of that?"). Each interview was conducted in a relaxed

155 atmosphere using a classroom students were familiar with. Although the same questions were 
Perceptions of a Heutagogical Approach to Coach Development

156 asked in each interview, their order changed slightly depending on the direction each

157 discussion took (Patton, 2002). The interviews, which ranged in duration from 46-65 minutes

$158\left(M_{\text {duration }}=53.67\right.$ minutes, $\left.S D=10.26\right)$, were conducted by the first author and recorded in

159 their entirety using a digital voice recorder.

\section{Data analysis}

161 The open-ended responses to each survey, and any additional comments that were

162 made, were transferred to separate Microsoft Excel 2010 spreadsheets and each group

163 interview was transcribed verbatim, resulting in 86 single-spaced pages of word processed

164 text. After familiarizing himself with the material by reading the text several times, the first

165 author then conducted a line-by-line inductive content analysis (Maykut \& Morehouse, 1994;

166 Patton, 2002), aided by the data analysis software Nvivo 10, and following a three-stage

167 process (Chesterfield, Potrac, \& Jones, 2010; Côté, Salmela, Baria, \& Russell, 1993; Nelson,

168 Cushion, \& Potrac, 2013). First, information rich statements were identified as stand-alone

169 meaning units (Thomas and Pollio, 2002), then, they were listed and labelled, before being

170 compared for similarities and clustered together into raw data themes. Finally, the analysis

171 proceeded to a higher level of abstraction, whereby the raw data themes were built up into

172 larger and more general themes in a higher-order concept (Côté et al., 1993). This process

173 allowed for the constant refinement of the results until theoretical saturation occurred (Strauss

174 \& Corbin, 1998).

175 To contribute to trustworthiness, participants were invited to read the transcription of

176 their interview and confirm its accuracy, as well as modify or expand upon any points where

177 perceived ambiguity was identified (Sparkes, 1998). This provided an opportunity for

178 member reflections (Smith \& McGannon, 2017), during which, three participants offered

179 additional information. The second author reviewed the higher order themes and codes

180 generated by the first author, then both authors engaged in a collaborative analytic approach 
Perceptions of a Heutagogical Approach to Coach Development

181 (Bean \& Forneris, 2017), whereby the themes were refined and/or re-defined and the most relevant quotes for each theme were selected. Any coding discrepancies were discussed until agreement was reached and data saturation was deemed to have occurred when no new constructs were emerging from the data (Guest, Bunce, \& Johnson, 2006). A draft summary of results was emailed to the participants, who all confirmed them to be an accurate description of their experiences of the module. To promote resonance in the study, the results are accompanied by illustrative quotes to help readers interpret the data in the most meaningful and transferable way to them (Biddle, Markland, Gilbourne, Chatzisarantis, \& Sparkes, 2001).

\section{Results}

In total, 19 of the 26 student-coaches enrolled on the module completed the end of module survey. Eighteen (94.74\%) believed their peers were a useful source of learning, with $14(73.68 \%)$ finding their group blog interesting and connected to their learning, $16(84.21 \%)$ saying they felt able to share their knowledge with others on the module and $15(78.95 \%)$

195 feeling they were developing skills they could apply outside of university. Sixteen (84.21\%)

196 student-coaches said they felt in control of their own learning on the module, with 14

197 (73.68\%) believing group blogs as used on the module provided a supportive context for their learning and $15(78.95 \%)$ perceiving that the module had helped them become a more reflective thinker and practitioner. Twelve $(63.16 \%)$ student-coaches felt the module had

200 helped them better understand general course content, with 17 (89.47\%) feeling the module

201 had helped them construct new knowledge and 18 (94.74\%) believing the module had given them a better understanding of how they learn. Ten (52.63\%) student-coaches agreed the module had helped them to feel connected to their peers. resulted in 32 raw data themes representing the student-coaches' articulation of their 
Perceptions of a Heutagogical Approach to Coach Development

206

207

208

209

210

211

212

213

214

215

216

217

218

219

220

221

222

223

224

225

226

227

228

229

230

experiences on the module (see Table 2). These were organized into 10 lower order themes and, finally, three higher order themes: (a) attitudinal disposition, (b) knowledge and experience, and (c) skill set. Although the results are presented as three separate themes, they are inter-related and there is overlap across all of them. Pseudonyms were created to protect participants' anonymity and are used with the supporting quotations throughout the following sections. Quotes from survey responses, which were anonymous, are identified by a "SR" in parentheses.

\section{Attitudinal Disposition}

Attitude toward group blogging. Some student-coaches described how they disliked or did not enjoy the blogging element of the module, and therefore avoided it. For example, Ben explained that “because I didn’t enjoy it, I would avoid it as much as I could,” while Mark agreed "I wasn't a massive fan of blogging... so I felt like I'd just put it off as much as I could." This discontent was often linked to a preference for more discrete and explicit assignments that did not run over a prolonged period. In the words of Ben, "I'd rather just sit and do something, like constant, and get it done, rather than keep coming back to it" and David, "you know you can have like four or five days of just smashing that assignment and then that's it it's gone."

In contrast, several student-coaches said they enjoyed the peer discussion that blogging facilitated e.g., "I enjoyed it because it's a chance to talk about placement experience" (SR) and "after the first few (posts) I was just looking forward to someone commenting back and responding to them" (Lisa). Similarly, many student-coaches enjoyed the additional freedom and independence they perceived that blogging provided, especially when compared with more traditional coursework activities (e.g., written reports and essays). James summed up this perception when he suggested "you could be a bit more expressive...you didn't have to worry about constantly having to be referencing everything 
Perceptions of a Heutagogical Approach to Coach Development

231

232

233

234

235

236

237

238

239

240

241

242

243

244

245

246

247

248

249

250

251

252

253

254

255

and, you know, use long words and stuff," Lisa agreed, saying “it was a lot more expressive wasn't it, it was all about you and your thoughts and other people, it wasn't about, like kind of that monotonous assignment writing."

Notably, however, some student-coaches did not see the freedom the module provided in such a positive light, with Kevin suggesting "there is just so much freedom in the blogging...too much freedom." There also appeared to be differences in opinion when it came to the perceived usefulness of blogging for learning, with some student-coaches believing it to be useful, e.g., "it has helped me understand the academic theory underpinning the course" (SR) and "it helps me to develop and further my knowledge" (SR), while others believed it to be somewhat less than useful, with one student stating quite definitively "I don't learn well from group blogging” (SR).

Attitude toward structure. In contrast to the heutagogical approach taken on the module, several student-coaches exhibited a clear preference for much more frequent face to face and/or classroom based sessions. This seemed to be both in terms of a perceived learning benefit of more regular tutor-student contact e.g., "I guess for people who can learn this way it is better than 'normal' sessions/lecturers. However, for me personally I prefer tutor-led sessions" (SR) and attendance-based modules perceived as being "easier" e.g., "some people like to take the easy route...turning up is easy... they don't have to necessarily engage, they just have to turn up" (Jordan). Student-coaches also reflected on the influence of set deadlines on their behavior, with some being comfortable with a relatively distant final deadline date for their ongoing "regular" input and participation. For example, Molly observed "it didn’t really influence me, to be fair, I didn't really think about the deadline on it. I just tried blogging every week." However, some student-coaches were clear they much preferred more explicit and immediate instructions and/or guidelines on exactly what they needed to do and when, with many using the urgency of a deadline the dictate their engagement. For example, 
Perceptions of a Heutagogical Approach to Coach Development

256 David explained how "however long you feel you need to do an assignment you sort of just

257

258

259

260

261

262

263

264

265

266

267

268

269

270

271

272

273

274

275

276

277

278

279

280

set yourself up for the week before it and then you go 'right I'm going to smash it this week," while Michael added "if it had to be done by five o'clock that same day...I would be more motivated to do it, rather than, you know what, I've been to that lesson and I've got two weeks now to get it done." Some student-coaches also compared the greater autonomy offered on the module with the (in their eyes) distinct lack of "freedom" they had experienced at school and/or in college, with many actually preferring the latter. Craig perhaps summed this view up best when he explained:

At school, you didn't have a choice, you sort of had to be there... it was like nine until three o'clock...you were always in lessons...you would never have a time where you wouldn't be in a lesson...for me that's a set routine, I'd prefer that...I would rather have the structure and less control.

Self-confidence. Many student-coaches described the negative influence their peers could have on their engagement in the module. For example, several student-coaches felt inhibited by a desire to avoid offending their peers and held back from engaging when they otherwise might have as a result. For example, Jerry suggested that "you don't want to offend them," while Liz elaborated, explaining that how well you knew your peers would influence any interaction: “because I don't know them, I wouldn't want to critique their work like that, I wouldn't want to go 'well you could have done this and you could have done that,' I don't know them." Conversely, some student-coaches felt their motivation to participate in the module suffered due to the attitude of some of their peers e.g., "although very engaged, motivation has taken a hit when others aren't supportive or engaged" (SR). A number of student-coaches also outlined a clear desire for "someone else" to start or instigate discussion, with many happy to take a "back seat" and rely on their peers to risk "being wrong" first. For example, Jerry described how waiting “just sort of gives you an idea of what route you are 
going to go down, like if you look at other people's (posts) first, you think 'oh right, yeah, I'm going down the right lines,"' while Tony agreed, adding: that and maybe go off onto a different route...I couldn't do it off my own back, I couldn't go 'right, I'm going to go and read about constraints leadership' or something and write about it. Several student-coaches also made explicit reference to the need for "confidence" if they are to engage in the type of approach taken on the module, with one student-coach reporting "I didn't blog at all as much as I wanted to as I didn't feel at all confident with the idea of posting my views online" (SR), conversely, another student-coach said they "felt confident because I knew what needed to be said and knew the correct way in doing it" (SR). Motivation. A minority of student-coaches were clear that their main motivation to engage in the module was simply to learn and improve e.g., "I'm very engaged in my own learning as I want to continue to better myself at every opportunity there is" (SR) and "I feel I always want to learn and understand not just my thought but other peoples"” (SR). However, many more student-coaches were clear that the main motivating factor for what they did on the module and why, was their overall grade and degree classification e.g., "I am determined to get the best grades that I can...especially in 3rd year, I have upped my game and got myself more organized to ensure that I do the best that I can" (SR). In similar fashion, Craig made clear that "the grade is the ultimate thing...to get the grade that I want, I do the work by the time it is meant to be done." A student-coach's motivation also appeared to have a clear influence on their willingness to research and explore new or unfamiliar topics, which would be an expected outcome of a heutagogical approach (as a set curriculum is eschewed). For example, those student-coaches who were primarily motivated by learning for learning's sake appeared to be more willing to explore e.g., "I find it exciting and intriguing to explore new 
Perceptions of a Heutagogical Approach to Coach Development

306

307

308

concepts and ideas in general" (SR), whereas those student-coaches most motivated by grades appeared less willing, with Nina noting "I don't want to be sat there writing a blog, I hate anything to do with literature."

Personal standards and expectations. Many student-coaches described their frustration at the engagement of some of their peers on the module, feeling it was below the standards that could be reasonably expected on a module of this type e.g., "it was frustrating when others in the group didn't reply or get involved, even though it was an individual task...it relied on others to reply and this was frustrating when they didn't” (SR). Offering another perspective, Jordan suggested that some people lacked thought in their posts and "just blogged for the sake of it...it's not going to help anyone else, it's just going to be some boring drivel that's wasting time." Likewise, several student-coaches thought it was important to maintain what they perceived to be good "etiquette" during the module, especially when it came to the interactions with their peers. For example, Lisa described how “if I left it more than a day, I'd feel bad because I'd left it so long...I'd want to get on and comment back and try and see what's going on and continue the conversation," while Molly said:

If someone had posted, I would read theirs' at the time to have a look...maybe make a comment, and then post mine, you know, being a bit respectful...I didn't want someone else to think that I didn't respect their opinion.

Many of the student-coaches who exhibited this frustration also appeared to be those most keen to take responsibility for their own development, as opposed to relying on their peers or tutors for direction. One student-coach described how "it's down to you. Every module you should be in control of your own learning and if not, then something is wrong. I felt I was in control" (SR), while another said, "I like this way of learning as it is basically off our own 
Perceptions of a Heutagogical Approach to Coach Development

330 back...it's up to us to ensure that we stick to deadlines and get the work done without been

331 (sic) spoon fed" (SR).

332 General views on learning. The students-coaches' general views and perceptions

333 about learning appeared to influence their expectations of, and experiences on, the module. In

334 particular, those student-coaches who felt most comfortable being outside of their "comfort

335 zone" and with ambiguous content and situations, seemed to value the module more and take

336 more from it. For example, one student-coach described the module as "challenging, but in a

337 good way" adding that "to learn I believe you need to be challenged and push myself" (SR),

338 while Matthew highlighted his attitude toward nuance and uncertainty when he said, "I like

339 that though, when there's no right or wrong answer." As a result of undertaking the module,

340 some student-coaches appeared to see the value of applied experience and reflection more

341 than they had done before. For example, one student-coach suggested that the module

342 "encourages us to reflect on what we have done which has massively benefitted me as it has

343 allowed me to become a somewhat better coach" (SR), while another stated they were "a lot

344 more reflective than I was 12 months ago and the continued blogging has helped this" (SR).

345 Those student-coaches who valued their peers as a source of learning also appeared to

346 benefit more from the module, in Michael's words "that helped...from your peers you can get

347 a different point of view...you can get different opinions", with another student noting "it's

348 good to be able to see how other students interpret questions and themes that you are

349 confused by" (SR). However, some students-coaches' experience on the module appeared to

350 be negatively influenced by what they perceived the role of the tutor to be, namely - that of a

351 "provider of knowledge" as opposed to a "facilitator of learning." For example, Jerry

352 explained how he found the module “frustrating, because...it takes longer. You know, you've

353 got to go and do it yourself, while, you know, you could have told me what X is and I go and

354 write a blog on it, that's easy," with Bill agreeing, adding: 
Perceptions of a Heutagogical Approach to Coach Development

355

356

357

358

359

360

361

362

363

364

365

366

367

368

369

370

371

372

373

374

375

376

377

378

I prefer that I turn up and you give us it and I write everything down and then leave. I would rather come to a lecture, you tell us what to do, I write it all down, and I go away and do a blog.

\section{Knowledge and Experience}

Requisite knowledge. There was a perception among many student-coaches that worthwhile and productive discussion with their peers on a given topic required a foundation of knowledge to be in place and that, without that knowledge base, they struggled to participate. This was especially apparent both in terms of content knowledge e.g., 'I didn't understand the themes and felt confused reading people's blogs" (SR) and on knowledge of appropriate written vocabulary to facilitate effective discussion, for example:

Through text it is very hard to put your opinion across and for it to come across in the way you express, so sometimes others can misinterpret what you're trying to say and it can become challenging and knock your confidence further (SR).

Many student-coaches also suggested that the depth of knowledge required to engage in the module was greater than they were used to, especially those student-coaches who had previously studied on a foundation degree. For example, Ailsa was adamant the module was “just a totally different level...I just feel, like we've said before...it's just a totally different level from the foundation degree," while Bill recounted how "I think me and Matthew were sort of like, it's a bit of a reality check to what we had to do and what we had to step up to." Prior experience. Many student-coaches felt they had never had to be independent in their studies before, and struggled to get to grips with the module under study as a result. For example, several compared the module with their prior educational experiences, especially at college. In Bill's words “everything we did was in a classroom, we never did anything on our own...we'd always do work in lessons as well, and coming into the blog it's sort of like...it's 
Perceptions of a Heutagogical Approach to Coach Development

379 a bit of a reality check." Matthew agreed, and described how he felt ill-prepared for this type

380 of module, saying:

381 It was quite disappointing actually, because we had been told by other students who came here from [feeder college], they said, 'it's a bit of a step up,' in terms of independent learning and stuff like that...I think for us, especially...that independent learning, and adaptability...you had to adapt quick.

This lack of experience also related to the type of assignment utilized on the module (i.e., reflective group blogging), which was ongoing and undertaken over a prolonged period, as opposed to a "one-off" written assignment (i.e., an essay, report etc.) or presentation. For example, Mark described how: When we did a foundation degree... we didn't do any blogging or anything like that, it was all assignments or presentations, or practicals...I'm not used to constantly doing the same thing...if I had an assignment I wouldn't do it two months prior and just to do little bits.

Similarly, a common theme was an assertion by those student-coaches that they had largely been "spoon-fed" during their previous educational experiences, including some other degree modules they were studying. This contrasted sharply with their experiences on the module under study, for example, Ailsa was adamant that "there is no comparison (laughing)...in college you ask a question and you are given an answer...you are spoon fed, and then you are totally just chucked in the deep end here," while Tony recounted: I remember at the start of college, I got a big book about that thick with everything in, and you literally reworded every answer to what they had written in the book, and you just put it into an assignment, and that was it, you got a distinction!

402 Jerry added that when studying for A' levels "you were just regurgitating what someone else 403 has already told you." 
Perceptions of a Heutagogical Approach to Coach Development

\section{Skill set}

Practical skills. Some student-coaches found that broadening their knowledge by reading around and researching a topic was difficult due to their lack of ability at finding appropriate literature. As such, they found it difficult to provide evidence that would underpin their ideas and expand upon the ideas of others. This was perhaps best expounded by Tony when he said:

I struggled to add anything to anybody else's blog because I'd really struggle to find any (literature)... and it wasn't because it's not there, it's just me, it was my ability to find that literature. So, I struggled to engage as much as I should have done really. Similarly, another student-coach suggested "the research was tough to find" (SR). Several survey comments also suggested that some additional software skills would have helped those motivated to engage with others' blogs in detail e.g., "I struggled with videos and pictures etc. and sometimes putting my posts in the correct category" (SR). Self-regulation skills. Many student-coaches suggested that self-discipline was a key skill that was required if one was to excel within a heutagogical framework. For example, Tony was clear "self-discipline, I think it's massive...I think if it's taught anything it's taught that...the self-motivating, the self-discipline...you have got to be organized, you've got to do everything...it's up to you...it's been so much harder," while Liz reinforced this view when she said:

It was forgettable... There were a lot of times where after like a couple of weeks I'd be like 'oh crap, I haven't blogged, I need to blog' and then I would panic...I think you had to be disciplined with yourself.

Time management was also mentioned by several student-coaches as a core skill required to succeed on the module. For example, David admitted that "my time management was nowhere near as good as Jordan's or someone who could just go back to it the next day 
without forgetting," while Ben described how "I leave things late, I always have, I probably shouldn't, but I always leave things as late as I can, and obviously with the blog you can't." It also appeared that time management became more of an issue at different times during the academic year, particularly when assignments were due on other modules, at which time some student-coaches struggled to manage their workload. For example, the assignments on other modules appeared to take priority, largely as they were perceived to be more “important.” Indeed, one student-coach described how "sometimes when other assignments were due, I would say in my mind it (group blog) definitely took a back seat, whereas if it was an essay it wouldn't have" (SR), while Liz explained "it was the last thing on my mind, other assignments were more of a priority than this one...you could tell nobody wrote anything when big stuff was on." In attempting to remedy some of these time management issues, several student-coaches explained that their ability to establish effective habits and routines played a key role. For example, Ailsa described how she set up her WordPress notification settings "so that I got an email each time somebody blogged, and it was duly down to me to obviously go on and read it and discuss it and look into it," while Jordan said: I don't want to sound harsh, but I think I was a bit more organized so I could keep track of it...at the end of the night coming in from coaching, just have a quick look and thinking 'oh I might just put a little comment down,' or a just question, just to prompt something. heutagogical approach to learning. The findings reveal that performance on, and perceptions 451 of, the module showed the approach to be differentially effective. For some student-coaches 452 (especially those transitioning from a foundation degree), the module appeared to be 453 distinctly unenjoyable and the heutagogical learning approach taken did not appeal to them. 
Perceptions of a Heutagogical Approach to Coach Development

454 Indeed, many of these student-coaches seemed to perceive the reason they struggled on the module was directly because of their prior educational experiences (e.g., at school and college), which appeared to value procedural, competency based learning and assessment, a "model" not uncommon in many coach accreditation and development systems (Collins et al., 2015). For many of these student-coaches, it seems that the outcome goals of what they were doing on the module (and their degree programme) were also a key mediator of their experiences. For example, many of the student-coaches who "struggled" on the module were, by their own admission, there "just" to tick the boxes required to obtain their final degree award. It appears the heutagogical approach to learning design taken in the current study might not be conducive to that.

In contrast, however, several other student-coaches evidently enjoyed the module and the opportunities afforded by the heutagogical approach were both positive and transformational. This group differed from those who were less complimentary about their experiences in several ways. For one, they seemed more inclined to want to learn for the sake of learning, and their expressed commitment and satisfaction with the new levels of challenge they experienced were another distinguishing characteristic. Returning to the aims of the present study, these differences therefore need to be considered against any claims made for a heutagogical approach to coach education. Notably, heutagogy is said to develop knowledge and skills (competencies) and capabilities (the ability to use them appropriately and effectively in novel situations, Stoszkowski \& Collins, 2017). Our results suggest that, at 474 least in this relatively short period of exposure, this did not take place. Rather, it seems student-coaches might require both competencies and capabilities "up front" in order to benefit from a heutagogical approach, that is a set of prerequisite appropriate knowledge,

477 possession of an appropriate skill set and an attitudinal disposition/willingness to use them.

478 Of course, it remains to be seen if earlier exposure to this learning approach, coupled perhaps 
Perceptions of a Heutagogical Approach to Coach Development

479

480

481

482

483

484

485

486

487

488

489

490

491

492

493

494

495

496

497

498

499

500

501

502

503

with the "front loading" of requisite knowledge, skills and attitude, would make the method more universally acceptable and effective. For the moment, however, the concerns raised by Stoszkowski and Collins (2017) would appear to hold some validity. Heutagogy is not a universal panacea, or perhaps, not yet!

\section{Conclusion}

Assuming that the approach taken on the module was genuinely heutagogic, and that our method of collecting feedback was open enough (both, we believe, fair assumptions), the present study suggests heutagogy is a potentially useful method in coach education and development. However, we have also highlighted what for us are some essential caveats to the use of what is an immensely appealing and face valid method. There is clearly a lot of "it depends-ness" in it, and several implications fall out of this.

Firstly, there is a need to consider the results against the outcome measures often used in coach education and accreditation (Mallett, Trudel, Lyle, \& Rynne, 2009): specifically, how well do the demonstrated benefits of the heutagogic approach taken match the evaluations most commonly used? Notably, application of a traditional knowledge based test in this case may well have resulted in poor scores for those coaches who benefitted most from this approach. Indeed, against the short term aims employed in most sport's governing body awards, what is "good" knowledge or skill or attitude? Some of these factors are easier to measure than others; however, we perhaps tend to the easier to assess (for a range of reasons). Therefore, coach educators may have to tolerate low "marks," at least initially, when employing this type of approach.

Secondly, we should stress the tendency for the coach education and development field to embrace new approaches; perhaps uncritically and prematurely (Stoszkowski \& Collins, 2014). Traditional learning approaches, and certainly formal coach education, has come in for substantial criticism in the recent literature (Nelson, Cushion, \& Potrac, 2013), 
504 but are we certain that it is less effective? Surely it depends. Could heutagogy be another 505 potentially evangelical push toward a specific method of developing coaches? It is but one of 506 several methods and coach developers must know the limitations of it as well as what the

507 potential precursors to its' successful use might be. In this regard, we would support an

508 approach that looks for overlap between approaches and develops a more nuanced inclusive

509 model (cf. Abraham \& Collins, 2011), albeit with a strong theoretical and evidence-grounded

510 base. As stated earlier, andragogy has something to offer, even without a wholesale change to

511 a new system! Perhaps more hybrid models are the way forwards, especially when the longer

512 term development of coaches across a pathway is considered.

513 Finally, and with regard to the particular coach development context employed in this

514 study (i.e., a bachelor degree programme), there is a potential 'socio-political goals' position

515 that must be considered. Namely, the "what's the point of education?" tautology. Is the aim to

516 simply get through the process with the best degree possible and get a well-paying job? This

517 is a fairly utilitarian and (perhaps) sensible view, especially if (at the time of writing) a

518 student in the UK is "investing" upwards of $£ 27,000$ in tuition fees alone across a three-year

519 bachelor degree programme - there are obvious benefits to coming through the system with a

5201 st class versus a $3^{\text {rd }}$ class degree after all (Tomlinson, 2008). As such, it is certainly a

521 perspective common amongst those starting on the educational pathway, whether through

522 degree study or a NGB system. However, as educators, we would surely aspire to more than

523 that. This is where we are in complete agreement with our colleagues in terms of heutagogy.

524 Nevertheless, it is an exceptional individual who recognizes the need for relativism,

525 especially at an early stage: this is not a normal thing (cf. Entwistle \& Peterson, 2004). For

526 approaches such as heutagogy to gain a hold, there seems to be a necessity to educate coaches

527 to a level so that they see a need for relativism (Collins, Abraham, \& Collins, 2012). In

528 summary, to educate towards and to realize the potential advantages of a heutagogical 
Perceptions of a Heutagogical Approach to Coach Development

529 approach to learning. Where this might best fit within a development pathway or coaching 530 career will be the topic of a subsequent paper. 
Perceptions of a Heutagogical Approach to Coach Development

\section{References}

Abraham, A., \& Collins, D. (2011). Taking the next step: Ways forward for coaching science. Quest, 63(4), 366-384.

Ayres, M., Price, A., Monk, A., \& McCarthy, L. (2016). Using a heutagogical approach to develop an undergraduate GCA module: Developing GCA V2. Thematic Symposia, Research Quarterly for Exercise and Sport, 87:sup1, S35.

Bean, C., \& Forneris, T. (2017). Examining the role of needs support in mediating the relationship between programme quality and developmental outcomes in youth sport. International Journal of Sport and Exercise Psychology.

Biddle, S. J. H., Markland, D., Gilbourne, D., Chatzisarantis, N. L., \& Sparkes, A. C. (2001). Research methods in sport and exercise psychology: Quantitative and qualitative issues. Journal of Sport Sciences, 19, 777-809.

Canning, N. (2010). Playing with heutagogy: Exploring strategies to empower mature learners in higher education. Journal of Further and Higher Education, 34(1), 59-71.

Chesterfield, G., Potrac, P., \& Jones, R. (2010). 'Studentship' and 'impression management' in an advanced soccer coach education award. Sport, Education and Society, 15, 299314.

Collins, D., Abraham, A., \& Collins, R. (2012). On vampires and wolves: Exposing and exploring reasons for the differential impact of coach education. International Journal of Sport Psychology, 43, 255-271.

Collins, D., Martindale, A., Burke, V., \& Cruickshank, A. (2015). The illusion of competency versus the desirability of expertise: Seeking a common standard for support professions in sport. Sports Medicine, 45(1), 1-7. 
Perceptions of a Heutagogical Approach to Coach Development

Collins, L., \& Collins, D. (2016). Professional judgment and decision making in the planning process of high level adventure sports coaching practice. Journal of Adventure Education and Outdoor Learning, 16(3), 256-268.

Côté, J., Salmela, J. H., Baria, A., \& Russell, S. H. (1993). Organizing and interpreting unstructured qualitative data. The Sport Psychologist, 7(2), 127-137.

Creswell, J. W. (2007). Qualitative inquiry and research design. Thousand Oaks, CA: Sage.

Cushion, C. J., Nelson, L., Armour, K. M., Lyle, J., Jones, R. L., Sandford, R., \& O’Callaghan, R. (2010). Coach learning \& development: A review of literature. Leeds, UK: Sports Coach UK.

Dillman, D.A. (2000). Mail and internet surveys: The tailored design method. New York, NY: Wiley.

Entwistle, N. J., \& Peterson, E. R. (2004). Conceptions of learning and knowledge in higher education: Relationships with study behaviour and influences of learning environments. International Journal of Educational Research, 41, 407-428.

Fraenkel, J. R. (2006). How to design and evaluate research in education. New York, NY: McGraw-Hill.

Guest, G., Bunce, A., \& Johnson, L. (2006). How many interviews are enough? An experiment with data saturation and variability. Field Methods, 18(1), 59-82.

Hase, S., \& Kenyon, C. (2000). From andragogy to heutagogy. Ultibase Articles. Australia: Southern Cross University.

Knowles, M. S. (1970). The modern practice of adult education: Androgogy versus pedagogy. New York, NY: Association Press.

Knowles, M. (1975). Self-directed learning: A guide for learners and teachers. Newmarket, ON: Prentice Hall. 
Perceptions of a Heutagogical Approach to Coach Development

Lara-Bercial, S., Abraham, A., Colmaire, P., Dieffenbach, K., Mokglate, O., Rynne, S., \& Nordmann, L. (2016). The international sport coaching bachelor degree standards of the international council for coaching excellence. International Sport Coaching Journal, 3(3), 344-348.

Mallett, C. J., Trudel, P., Lyle, J., \& Rynne, S. B. (2009). Formal vs. informal coach education. International Journal of Sports Science and Coaching, 4(3), 325-364.

Maykut, P., \& Morehouse, R. (1994). Beginning qualitative research: Qualitative data analysis: An expanded sourcebook. Thousand Oaks, CA: Sage.

Millward, L. (2012). Focus groups. In G. Breakwell, J. Smith, \& D. Wright (Eds.), Research methods in psychology (pp. 411-437). Thousand Oaks, CA: Sage.

Nelson, L., Cushion, C., \& Potrac, P. (2013). Enhancing the provision of coach education: The recommendations of UK coaching practitioners. Physical Education and Sport Pedagogy, 18(2), 204-218.

Patton, M. Q. (2002). Qualitative research and evaluation methods. Thousand Oaks, CA: Sage.

Smith, B., \& McGannon, K. R. (2017). Developing rigor in qualitative research: Problems and opportunities within sport and exercise psychology. International Review of Sport and Exercise Psychology, http://dx.doi.org/10.1080/1750984X.2017.1317357

Sparkes, A. (1998). Validity in qualitative inquiry and the problem criteria: Implications for sport psychology. The Sport Psychologist, 12, 363-386.

Sports Coach UK (2015). UKCC Support Guide - Levels 1-4. Leeds, UK: Sports Coach UK.

Stoszkowski, J., \& Collins, D. (2014). Communities of practice, social learning and networks: Exploiting the social side of coach development. Sport, Education and Society, 19(6), 773-788. 
Perceptions of a Heutagogical Approach to Coach Development

Stoszkowski, J., \& Collins, D. (2015). Using shared online blogs to structure and support informal coach learning. Part 1: A tool to promote reflection and communities of practice? Sport, Education and Society, 22(2), 247-270.

Stoszkowski, J., \& Collins, D. (2016). Sources, topics and use of knowledge by coaches. Journal of Sport Sciences, 34(9), 794-802.

Stoszkowski, J., \& Collins, D. (2017). Nirvana or never-never land: Does heutagogy have a place in coach development? International Sport Coaching Journal, 4(3), 353-358.

Strauss, A., \& Corbin, J. (1998). Basics of qualitative research. Thousand Oaks, CA: Sage.

Thomas, S. P., \& Pollio, H. R. (2002). Listening to patients: A phenomenological approach to nursing research and practice. New York, NY: Springer.

Tomlinson, M. (2008). 'The degree is not enough': Student perceptions of the role of higher education credentials for graduate work and employability. British Journal of Sociology of Education, 29(1), 49-61.

Willis, G. B., DeMatio, T. J., \& Harris-Kojetin, B. (1999). Is the bandwagon headed to the methodological Promised Land? Evaluating the validity of cognitive interviews. In M. G. Sirken, D. J. Hermann, S. Schechter, N. Schwarz, J. M. Tanur, \& R. Tourangeau (Eds.), Cognition and research (pp. 133-153). New York, NY: Wiley. 
Perceptions of a Heutagogical Approach to Coach Development

Table 1

Participant Demographics

\begin{tabular}{|c|c|c|c|c|c|}
\hline Participant & $\begin{array}{c}\text { Age } \\
\text { (years) }\end{array}$ & Gender & Coach Level & Sport & $\begin{array}{c}\text { Experience } \\
\text { (years) }\end{array}$ \\
\hline Ailsa & 21 & $\mathrm{~F}$ & L2 & Soccer & 5 \\
\hline Peter & 22 & M & L2 & Soccer & 5 \\
\hline James & 22 & M & L2 & Rugby League & 4 \\
\hline Steven & 21 & M & L1 & Soccer & 3 \\
\hline Lisa & 21 & $\mathrm{~F}$ & L2 & Soccer & 5 \\
\hline Mark & 21 & M & L1 & Soccer & 3 \\
\hline Ben & 21 & M & L1 & Soccer & 3 \\
\hline Paul & 21 & M & L2 & Rugby Union & 4 \\
\hline Tommy & 21 & M & L1 & Soccer & 3 \\
\hline Nina & 21 & $\mathrm{~F}$ & L2 & Netball & 6 \\
\hline Roger & 22 & M & L2 & Soccer & 4 \\
\hline Jerry & 21 & M & L1 & Soccer & 3 \\
\hline Robin & 22 & M & L1 & Rugby League & 3 \\
\hline Matthew & 23 & M & L2 & Soccer & 4 \\
\hline Tony & 23 & M & L2 & Rugby Union & 4 \\
\hline Bill & 21 & M & L2 & Soccer & 4 \\
\hline $\mathrm{Liz}$ & 24 & $\mathrm{~F}$ & L1 & Netball & 5 \\
\hline Sophie & 21 & $\mathrm{~F}$ & L1 & Multisport & 3 \\
\hline David & 21 & M & L1 & Soccer & 3 \\
\hline Kevin & 21 & M & L1 & Soccer & 3 \\
\hline Molly & 22 & $\mathrm{~F}$ & L1 & Martial Arts & 3 \\
\hline Jordan & 21 & M & L1 & Athletics & 3 \\
\hline Martin & 21 & M & L1 & Soccer & 3 \\
\hline Craig & 22 & M & L1 & Soccer & 3 \\
\hline Michael & 21 & M & L1 & Soccer & 3 \\
\hline Danny & 21 & M & L1 & Cricket & 3 \\
\hline
\end{tabular}


Table 2

Results of Qualitative Analysis of Raw Data.

\begin{tabular}{|c|c|c|}
\hline Raw Data Theme & Lower Order Theme & Higher Order Theme \\
\hline $\begin{array}{l}\text { Didn't enjoy so avoided } \\
\text { Enjoyment of more freedom and independence } \\
\text { Enjoy peer discussion } \\
\text { Preference for discrete one-off assignments } \\
\text { Perceived usefulness for learning }\end{array}$ & Attitude toward group blogging & Attitudinal disposition \\
\hline $\begin{array}{l}\text { Desire for face-to-face taught sessions } \\
\text { Influence of explicit deadlines } \\
\text { Preference for school-like structure }\end{array}$ & Attitude toward 'structure' & \\
\hline $\begin{array}{l}\text { Influence of peer dynamics } \\
\text { Reliance on initiative of others } \\
\text { Confidence }\end{array}$ & Self-confidence & \\
\hline $\begin{array}{l}\text { Desire to learn } \\
\text { Grade as major motivator } \\
\text { Willingness to research and explore new areas }\end{array}$ & Motivation & \\
\hline $\begin{array}{l}\text { Frustration at engagement of others } \\
\text { Importance of etiquette } \\
\text { Take responsibility for self }\end{array}$ & Personal standards and expectations & \\
\hline $\begin{array}{l}\text { Comfort with challenge and ambiguity } \\
\text { Perception of tutor's role } \\
\text { Value of applied experience and reflection } \\
\text { Value of peers for learning }\end{array}$ & General views on learning & \\
\hline $\begin{array}{l}\text { Discussion requires knowledge } \\
\text { Level of knowledge required }\end{array}$ & Requisite knowledge & Knowledge and experience \\
\hline
\end{tabular}


Perceptions of a Heutagogical Approach to Coach Development

\begin{tabular}{lll}
\hline Never had to be independent & Prior experience \\
Never had to do ongoing assignments & & \\
Spoon fed at school/college & & \\
\hline Research skills & Practical skills & \\
Competency with software & Self-regulation skills \\
\hline Establishment of habits and routines & & \\
Self-discipline & & \\
Time management & \\
Managing varying assignment workload & & \\
\hline
\end{tabular}

Managing varying assignment workload 